\title{
Estructura de la jurisdicción del futuro: una propuesta sistémica y holística
}

The jurisdiction structure of the future: a systemic and holistic approach

\author{
0 (O) \\ JAVIER EDUARDO JIMÉNEZ VIVAS ${ }^{1}$ \\ Corte Superior de Justicia de Lima Este \\ (Lima, Perú) \\ Contacto: jjimenezui@pj.gob.pe \\ https://orcid.org/0000-0001-7972-2804
}

\section{RESUMEN}

Los desafíos presentes y futuros de la función jurisdiccional lo son también de las organizaciones que integran el sistema de justicia y de toda la sociedad. Una respuesta jurisdiccional o solo de dichas organizaciones será insuficiente. Se necesita una visión sistémica y holística para cualquier política o gestión. El sistema educativo, la economía y las nuevas tecnologías son tres segmentos

1 El presente artículo ha sido redactado como continuación de las investigaciones del autor en materia de transformación digital frente a la sociedad y al derecho, no integra un proyecto mayor y fue financiado íntegramente por el autor. 
claramente comprometidos, pero de manera transformadora: su comunión permite esbozar una estructura jurisdiccional con una inserción sistémica diferente.

Palabras clave: educación; economía; tecnología; estructura jurisdiccional; sistema de justicia; futuro.

\section{ABSTRACT}

The present and future challenges of the jurisdictional function are also those of the organizations that integrate the justice system and of society as a whole. A jurisdictional response or the response of these organizations alone will be insufficient. A systemic and holistic vision is needed for any policy or management. The education system, the economy and new technologies are three segments clearly committed, but in a transformative way: their communion allows outlining a jurisdictional structure with a different systemic insertion.

Key words: education; economy; technology; jurisdictional structure; justice system; future.

Recibido: 11/05/2021 Aceptado: 25/05/2021

\section{IDEAS PRELIMINARES}

Nuestra función jurisdiccional enfrenta grandes desafíos. Sean de tipo tecnológico, cuestionamientos a su legitimidad, problemas en su organización, deficiencias presupuestarias o nuevas demandas sociales, su futuro muestra incertidumbres. La pandemia continúa y sigue complicando nuestra función: otros retos aparecerán. Llegó la hora de combinar reflexión y planteamientos de otra manera, de entender que tras esas dificultades se ocultan oportunidades. Son muchas las preguntas por atender. Una nueva manera de responder 
será necesaria. Pero antes tenemos que ensayar una nueva forma de ver la problemática, una más humana, más social y, por ende, más global, sistemática y holística.

Como jueces coordinamos de la mejor manera posible el trabajo de compañeros, vulnerables o no, pero hay quien enferma y debe abandonar toda labor, complicándola. La brecha digital es grande y nuestras organizaciones erigen respuestas con la mejor intención y con todo aquello que disponen, pero al frente el abogado debe esperar para ingresar un escrito, pues la red se sobrecarga, mientras la abogada no puede ingresar otro al no encontrar la opción precisa en el sistema. Muchas niñas y niños enfrentan restricciones cuyo final no asoma: la escuela como ambiente social y educativo se diluye, volcándose a la red y a pantallas de todos los tamaños y a toda hora, sin un claro control. El confinamiento, estricto o no, ha venido acompañado de sorprendentes cuotas de violencia familiar, con las consecuencias actuales, y ha dejado en la salud mental de nuestra sociedad heridas cuya profundidad ignoramos. La reapertura de actividades económicas nos ha devuelto al tradicional apiñamiento ambulante, al irresponsable conductor y al imprudente peatón. Un proceso electoral en pandemia obliga al Estado una vez más a gastar indicando cómo marcar la cédula o cómo numerar los votos preferenciales. El desempleo empobrece, genera emprendimientos, provoca endeudamientos y estimula frustraciones.

Y todo esto se presenta a la vez, más aquí o menos allá, el mes pasado o el siguiente. Es una problemática organizacional, educativa, económica, jurisdiccional, pero, antes que todo eso, es humana. Somos seres humanos quienes integramos las organizaciones, nos educamos, nos comportamos como agentes económicos y comparecemos como usuarios del servicio de justicia, entre otros que presta el Estado. El juez, la abogada, el niño, la mujer violentada, el vendedor ambulante, la electora, el conductor y la desempleada son personas. La problemática así definida impone medidas urgentes, 
pero también trascendentes. Es imprescindible atender lo urgente, pero la reducción de lo urgente y su devolución a la categoría de «excepcional», a donde pertenece, dependerá de ver también como imprescindibles el fondo, lo estructural. La sola gestión de lo urgente equivale al fracaso económico y, a la larga, a más problemas sociales y judiciales. Solo una política con todos sus actores, en todos los sectores comprometidos, paciente pero segura, podrá reposicionar ordenadamente aspectos estructurales.

El que acabamos de presentar es un gran desafío: largo, diverso, confuso y en general difícil, pero por todo ello no menos retador. Si este desafío no convoca lo mejor de nosotros, ¿qué otra cosa o tema lo hará? Es hora de dejar nuestros cargos, nuestros casos, nuestros empleos por solo un momento, con el fin de tomar decisiones que orienten nuestro futuro proceder como seres humanos, como abogados, como funcionarios, como organizaciones, como sociedad. En los párrafos que siguen va nuestra propuesta, con fundamentos propios y fuentes precisas, que se autodefinen como un punto inicial, solo un punto de una recta interminable que hay que recorrer.

Hay viajes que debemos emprender hoy, por nuestra voluntad y a nuestro ritmo, pues mañana tendremos que iniciarlos por obligación, con mayores y variados costos, con menos herramientas preparadas y con más desacuerdos.

\section{LA IMPRESCINDIBLE PREMISA EDUCATIVA}

Decir que todos los elementos que componen nuestras sociedades se labran en el sistema educativo es afirmar algo en lo que todos estamos de acuerdo. Con algunas excepciones, todos los ámbitos de la realidad mantienen una relación mediana o grande con la educación. Esta nos enseña a leer y escribir, nos introduce en el mundo de la matemática, nos muestra el arte y las ciencias, provee 
de técnicos y profesionales, oferta especialidades y mejora de competencias, etc. Más que todo eso, la educación forma a las personas: empieza en el hogar, acompaña nuestra niñez, adolescencia, juventud y, en buenos términos, nunca nos abandona. Escribir acerca del sistema educativo es referirnos tanto a la educación como a la instrucción.

La idea con la que termina el párrafo anterior, y el alcance global del sistema educativo sobre toda la sociedad, compromete a este inescindiblemente con el sistema de justicia. Es algo que todos sabemos, sin embargo, nunca lo hemos visto presentado a través de concretas variables. Para explicar esto mejor, para revelar los alcances de dicha relación, es prudente identificar algunos puntos de contacto entre ambos sistemas (seguramente son muchos más). Podemos encontrar estos en determinadas circunstancias sociales en las cuales hace crisis algún segmento de la educación. Estos supuestos evolucionan negativamente y generan un sinnúmero de consecuencias sociales y legales que luego se manifiestan en controversias judiciales de diversa tipología.

Una primera variable es la deserción escolar. Según la Estadística de la Calidad Educativa (ESCALE) del Ministerio de Educación, el porcentaje de alumnos matriculados en primaria ha sido del $83 \%$ (años 2013-2015), el 81.15\% (años 2015-2017) y el 73.7\% (años 2017-2019). La tasa de deserción permanente, entonces, fue del $17 \%, 18.85 \%$ y $26.3 \%$ en los mismos períodos, respectivamente. Esta tasa creciente no toca al 2020, primer año de la pandemia.

De acuerdo con la misma fuente estadística, el porcentaje de alumnos matriculados en el nivel de secundaria fue del 94.6\% (años 2013-2015), del 95\% (años 2015-2017) y del 93.3\% (años 20172019). La tasa de deserción permanente, entonces, fue del 5.4\%, 5\% y $6.7 \%$ en los mismos períodos, respectivamente. Esta tasa ascendente tampoco alcanza a la pandemia. 
¿Qué ocurre con los niños que dejan sus estudios primarios? ¿Qué sucede con los adolescentes que abandonan la secundaria? Un motivo importante - si no el principal - es su ingreso prematuro al mercado laboral en circunstancias desfavorables. Sigamos.

Un segundo elemento es, precisamente, el trabajo adolescente. El 11 de junio de 2019 (nueve meses antes del inicio de la pandemia), la Defensoría del Pueblo publicó la Nota de Prensa n. ${ }^{\circ}$ 175/OCII/ DP/2019 titulada «Defensoría del Pueblo advierte preocupante aumento del trabajo en adolescentes» con el siguiente texto:

- Urge garantizar el acceso y la continuidad en la educación de adolescentes que laboran pues políticas públicas de prevención no están funcionando.

- Se debe modificar el Código Penal, incorporando un delito especial que sancione la explotación laboral de menores de edad.

[...]

En los últimos años, el número de adolescentes entre 14 y 17 años que solo trabaja se ha elevado progresivamente, según el Inei. En 2017, el 7,7\% se encontraba en esta situación; en 2018, la cifra creció a 8,1\%; y en 2019 , escaló a 9,8 \%.

Similar panorama se observa en el grupo de adolescentes de 14 y 17 años de edad que trabaja y estudia. En 2017, el 19,2\% de menores de edad en este rango se encontraba en esta situación; en 2018, el porcentaje llegó a 23,1\% y para el primer trimestre de 2019 , subió a $23,9 \%$.

Por otro lado, en el año 2017, se registró una tasa de deserción escolar del 6,3\% en alumnos de secundaria de 13 a 19 años, según información del Ministerio de Educación.

Tal como terminó afirmando dicho comunicado oficial, la deserción escolar se relaciona con el trabajo adolescente, con el fenómeno del subempleo y con distintas formas de explotación. Todos los problemas acompañan o suman a los demás, esa es la constante. Un poco más allá, la población adolescente en etapa escolar puede 
ver comprometido su presente y su futuro de maneras más graves, con consecuencias sociales y legales también más onerosas.

Una tercera variable que debe tomarse en cuenta es el índice de adolescentes infractores. En una publicación oficial del año 2017, el Consejo Nacional de Política Criminal del Ministerio de Justicia realizó una evaluación de las «características sociales: educación, familia y trabajo» de los adolescentes infractores, e indicó que:

La mayor parte de los adolescentes [...] que no ha culminado la Educación Básica Regular - EBR ha visto interrumpido su formación escolar por la comisión de una infracción y la medida socioeducativa impuesta por el sistema de justicia juvenil. El 78.1\% no ha culminado la EBR. El 58.3\% $(2,170)$ tienen secundaria incompleta, el $10.1 \%$ (375) tienen primaria incompleta, el 8,7\% (325) primaria completa y el $1 \%$ (39) son analfabetos.

Esta interrupción deviene en efectos negativos para su desarrollo. Al respecto, UNODC señala que la privación de la libertad (para el caso de los adolescentes internados en un CJDR) genera un «déficit de destreza que les hace difícil competir y tener éxito en la comunidad: poca habilidad para las relaciones interpersonales, bajos niveles de educación formal, analfabetismo, funcionamiento cognitivo o emocional deficiente o falta de capacidad de planificación o gestión financiera.

Explorar el alto valor porcentual del grupo que no ha culminado la secundaria permite dar cuenta de otros factores como la mala experiencia o adaptación escolar (incluye su afinidad hacia la escolaridad y la capacidad de retención del sistema educativo), el desempleo, la exclusión social y los niveles de pobreza de los hogares, factores psicológicos o cognitivos vinculados con la autoestima, y las actitudes que tienen hacia la delincuencia. La educación es un mecanismo de integración social y un factor de protección para los adolescentes (pp. 19-20).

La importancia de la educación de los adolescentes, así como la relación entre su deserción escolar y la comisión de infracciones, 
aparece expresamente identificada. Las consecuencias jurídicas y procesales son variadas y numerosas. Pero estas muestran también secuelas de otro tipo, que comprometen otros aspectos de la sociedad y otros segmentos del ordenamiento jurídico.

Un cuarto elemento que se debe considerar es el endeudamiento juvenil, es decir, el endeudamiento de los nuevos mayores de edad. Sobre el tema, de acuerdo con una publicación efectuada el 3 de agosto de 2015 en el portal PQS, destinado a asesorar emprendimientos (que cita como fuente al diario Gestión), existirían en Perú

150,963 jóvenes de hasta 25 años que cuentan con una tarjeta de crédito. La cifra, de por sí, es llamativa teniendo en consideración que dicho rango de edad está asociado con trabajos de poca jerarquía o prácticas pre o profesionales. Sin embargo, este punto no es el sorpresivo. Resulta que el $50 \%$ de ellos, es decir 75,425 jóvenes, tiene atrasos en el pago de sus deudas (párr. 1).

Toda la información presentada pone de manifiesto las relaciones existentes entre la crisis del sistema educativo, la gestación de variados problemas sociales (hemos citado algunos) y la manifestación de estos a través del sistema de justicia (mediante una diversidad de procesos judiciales en las distintas jurisdicciones ordinarias); todo lo cual compromete las competencias del Poder Judicial, la intervención del Ministerio Público, la necesidad de la defensa pública y otros puntos del sistema. Más allá de ello, todos los componentes del sistema ven comprometidas sus estructuras organizacionales, sus infraestructuras (físicas y digitales), las competencias personales de sus integrantes, sus mecanismos de toma de decisiones, sus canales comunicativos y sus variados recursos. El intento de responder a los problemas sociales recién citados a partir de la acción del sistema de justicia equivale a ignorar el origen y la gestación de tales dificultades. Una verdadera política en ese sentido podría 
preciarse de ser tal si aborda tamaña problemática desde sus inicios. Considerar e involucrar al sistema educativo es imprescindible además de realista. Desde el faro educativo es mucho más lo que puede alumbrarse, divisarse y - por supuesto- hacerse.

Lo anterior impone una primera tarea: identificar temáticas, ámbitos y espacios de la formación educativa directamente involucrados en la posterior gestación de los problemas sociales presentados (son más, como queda indicado). Nos referimos a elementos que, por su importancia, tocan a todos los ciudadanos de manera individual, se relacionan con la sociedad y con organizaciones dentro de esta, y también se vinculan con los distintos niveles del Estado. Sin intentar cerrar la lista, hoy creemos que esos temas son los derechos fundamentales (también llamados derechos humanos en el ámbito internacional), la educación electoral, la educación vial, la educación tributaria y la educación financiera.

La innegable trascendencia teórica de los derechos fundamentales solo es superada por la urgente necesidad de formar a los futuros ciudadanos en su práctica. Todas las manifestaciones de desigualdad, de intolerancia y de violencia tienen en su base la ausencia de una conciencia social compartida acerca de los derechos fundamentales. Nos referimos a un estándar mínimo de conocimiento y práctica de los valores inmersos en tales derechos, que debe ser prioridad desde la educación primaria y que no debe abandonar los currículos académicos posteriores.

Lo anterior no es una novedad. El Código Procesal Constitucional, aprobado mediante Ley n. 28237 de 2004, establece en su sexta disposición final que

En todos los centros de enseñanza, de cualquier nivel, civiles, o militares, se impartirán cursos obligatorios sobre derechos fundamentales y procesos constitucionales. 
Compete promover y supervisar esta tarea al Ministerio de Educación; a la Asamblea Nacional de Rectores, y a los Ministerios de Defensa y del Interior. El Ministerio de Justicia queda encargado de la labor de publicación y difusión de la Constitución y textos básicos conexos (Congreso de la República, 2004, p. 18).

La norma legal citada avala íntegramente la noción sistémica que defendemos. El dispositivo establece la obligatoriedad de la enseñanza de los derechos fundamentales en todos los niveles educativos y compromete en dicha tarea a diversos sectores del Estado, con competencias inicialmente distintas, pero alineadas en la enseñanza y difusión de los derechos fundamentales (y de los procesos constitucionales a su servicio). Al ser órganos rectores los mencionados, la norma compromete también a todas aquellas dependencias descentralizadas a lo largo y ancho del país. Lo que hace falta es cumplir la norma, generalizando la teoría y la práctica de los derechos fundamentales como objetivo central, por encima tanto de los lineamientos comerciales que puedan preferir en los currículos una inversión educativa no alineada a los objetivos nacionales, como de la intención de una educación pública que intentando ser más «moderna» siga similar tendencia.

Escribir sobre la adolescencia es referirnos a futuros jóvenes y ciudadanos, ante quienes la educación electoral cobra importancia. Es lamentable ver cómo las personas, ante un proceso de elecciones políticas, muestran siempre las mismas dudas frente a diversos detalles asociados al ejercicio del derecho al voto. Es lamentable también ver cómo el Estado tiene que distraer recursos en atender esa brecha con variada información electoral; pero es más triste comprobar que los efectos de dicha inversión son solo momentáneos: nuevos comicios políticos exigen nuevas campañas informativas y el ciclo se repite una y otra vez. El tema no ha sido agendado como problema público, debido a lo cual nunca se ha diseñado una 
política para su solución. La educación secundaria - al menos- es una oportunidad para asumir el asunto con seriedad y efectividad.

Pero la ciudadanía se ejerce en sociedad, la cual para su diario caminar reclama de los ciudadanos una mínima pero sólida educación vial. Nos referimos aquí a todo lo relacionado con el empleo de las vías públicas, sean carreteras, avenidas, calles, parques, veredas, señalización de vías, mobiliario urbano, uso de transporte público, entre otros. Se trata de ámbitos de convivencia social y de práctica de la ciudadanía que no podemos soslayar, que hacen crisis a través de toda la variedad de procesos judiciales asociados a su mal empleo. Aquí también indicaremos que tanto la educación primaria como la secundaria son dos buenas oportunidades para hacer del posterior recurso al sistema de justicia uno más equitativo, más preciso y demandante de menos recursos públicos.

Hay dos segmentos más de necesaria consideración. Uno es la educación tributaria, básica para que nuestros futuros ciudadanos conozcan de ese relacionamiento con el Estado, imprescindible para la producción de bienes públicos (concepto al que volveremos luego) y que mal llevado puede generar serias dificultades a cualquier ciudadano. Otro es la educación financiera, a fin de que nuestros adolescentes comprendan las ventajas que puede deparar una buena conducción de nuestras finanzas privadas, así como los posibles problemas que pueden surgir en caso contrario. Los endeudamientos solo generan más litigiosidad, estrés, costos de oportunidad y distraen un buen segmento de los recursos del sistema de justicia.

Gran parte de los conceptos citados en relación con el sistema educativo son avalados por instrumentos de gestión del sector. Comprobemos ello.

El Currículo Nacional de la Educación Básica aprobado por Resolución Ministerial n. ${ }^{\circ}$ 281-2016-ED (vigente este 2021) establece 
varios retos para la educación básica y el perfil de egreso, los enfoques transversales para el desarrollo del perfil del egresado, las definiciones claves para el desarrollo de dicho perfil y los estándares nacionales de la educación básica, bajo la forma de 28 competencias (Ministerio de Educación, 2017).

Entre los enfoques transversales figura el «enfoque de derechos», el cual considera el valor denominado "conciencia de derechos», que comprende las actitudes de «Disposición a conocer, reconocer y valorar los derechos individuales y colectivos que tenemos las personas en el ámbito privado y público» (Ministerio de Educación, 2017 , p. 20). Los valores «libertad y responsabilidad» suponen la «Disposición a elegir de manera voluntaria y responsable la propia forma de actuar dentro de una sociedad» (Ministerio de Educación, 2017, p. 20). Seguidamente, el «enfoque de interculturalidad» comprende el valor de «justicia», que se refiere a la «Disposición a actuar de manera justa, respetando el derecho de todos, exigiendo sus propios derechos y reconociendo derechos a quienes les corresponde» (Ministerio de Educación, 2017, p. 22). Por su parte, el «enfoque ambiental» cuenta con el valor de «justicia y solidaridad» consistente en la «Disposición [...] a actuar en beneficio de todas las personas, así como de los sistemas, instituciones y medios compartidos de los que todos dependemos» (Ministerio de Educación, 2017, p. 25).

Entre las competencias que definen los estándares nacionales de la educación básica se lee «Convive y participa democráticamente», que comprende las siguientes conductas:

- Interactúa con todas las personas

- Construye y asume acuerdos y normas

- Maneja conflictos de manera constructiva

- Delibera sobre asuntos públicos

- Participa en acciones que promueven el bienestar común (Ministerio de Educación, 2017, p. 33). 
Otra competencia es «Gestiona responsablemente los recursos económicos», por la cual el estudiante:

- Comprende las relaciones entre los elementos del sistema económico y financiero

- Toma decisiones económicas y financieras (Ministerio de Educación, 2017, p. 33).

Vemos cómo el Currículo Nacional de la Educación Básica desarrolla de manera directa o indirecta los tópicos que antes hemos mencionado, solo serían necesarios algunos ajustes y agregados para que la equivalencia sea casi total, además de lo más importante: acciones concretas para su cumplimiento. Podemos concluir entonces que el sistema educativo debe asumir el rol de necesaria etapa previa al sistema de justicia, con carácter formativo, preventivo y concientizador.

\section{EL NECESARIO COMPONENTE ECONÓMICO}

La economía es la ciencia de la escasez o, mejor dicho, de los recursos escasos; por ello es también la ciencia que estudia la manera en que las sociedades deciden la forma de utilizar tales recursos. En ese sentido, son cuatro las cuestiones fundamentales que como ciencia debe responder: ¿qué ha de producirse?, ¿cómo ha de producirse?, ¿para quién ha de producirse?, y ¿cómo se toman estas decisiones? La primera de las interrogantes compromete a su vez diversas preguntas, una de las cuales es decidir si determinado bien se debe producir en el sector público o el sector privado (Stiglitz y Rosengard, 2016, p. 43). En economía, la palabra «bien» engloba aquella de «servicio».

La decisión de producir un bien en el sector público o el sector privado - de distinguir si un bien será público o privado- pasa por identificar si en su consumo existe rivalidad o no y si en su consumo se puede introducir una exclusión o no. Existirá rivalidad 
en el consumo de un bien en el caso que, habiendo sido utilizado por una persona, no pueda ser utilizado por otra (ejemplo: si tomo un jugo, este ya no puede ser ingerido por otra persona); por el contrario, no habrá rivalidad en los casos en los que el consumo de una persona no impide o reduce el consumo de otra (ejemplo: la defensa nacional de un Estado presta el mismo servicio y cuesta lo mismo si nace un niño más o si emigra una persona más a nuestro país). Habrá exclusión cuando sea posible retirar a una persona de los beneficios de un bien (ejemplo: si compro una computadora personal, todas las demás personas quedan excluidas de los beneficios de dicho artefacto); no habrá exclusión cuando tal posibilidad no exista (ejemplo: no es posible excluir a un barco que navega cerca de un faro de los beneficios que este proporciona) (Stiglitz y Rosengard, 2016, p. 148).

Concluyendo, en términos generales, los bienes privados tienen las propiedades de consumo rival y de exclusión, los bienes públicos puros se caracterizan por el consumo no rival y la imposibilidad de excluir personas de sus beneficios; existen también los bienes públicos impuros, en los cuales no hay rivalidad, pero es posible introducir ciertas exclusiones (Stiglitz y Rosengard, 2016, pp. 148 y 153). En el caso de los bienes públicos impuros, el Estado suele cobrar una tasa a quienes se benefician de los bienes que produce, como parte del financiamiento de su producción (Stiglitz y Rosengard, 2016, p. 149). Conforme a lo antes precisado, dentro de los bienes públicos impuros se ubican los servicios con esa característica.

Creo que nuestros lectores ya adivinaron hacia dónde vamos. Sí, dentro del marco de la terminología económica empleada, en nuestro servicio de justicia, por un lado, no existe rivalidad en su consumo, pues el uso del servicio por una persona (que alguien presente una demanda, por ejemplo) no impide a las demás utilizar 
el servicio (ninguna otra se ve impedida de presentar su propia demanda). Por otro lado, es posible introducir exclusiones que influyen directamente en el acceso al servicio (dos ejemplos: todas las normas procesales enuncian requisitos de admisibilidad y existe una regulación anual de tasas judiciales).

Aclarado ello, vamos al problema. Es sabido que el Poder Judicial siempre tiene dificultades presupuestarias. El presupuesto público asignado y las tasas cobradas en todo el país (que conforman su financiamiento) no han sido suficientes para dotar a la organización de una adecuada (y propia) infraestructura - en cantidad y calidad-, no han permitido desarrollar una adecuada arquitectura digital e impiden dotar de los recursos manuales y técnicos necesarios (eso que todos llamamos «logística») sin perjuicio de brechas salariales, conceptos impagos y otras dificultades. Exigir más recursos y generar ingresos propios es necesario, pero quizá la solución no se encuentre solamente en ello. Veamos.

La idea recién mencionada, según la cual el Poder Judicial opera y se financia con un presupuesto anual y con los ingresos que percibe a título de tasas, constituye un axioma, es decir, una idea indiscutida, pero además indiscutible, pues no existe el planteamiento - por lo menos en nuestro país - de cómo el Poder Judicial podría operar sin ambas fuentes de sustento económico. Expresado de otra manera, la prestación del servicio de justicia requerirá de una previa inyección económica de parte del Estado y de un aporte concurrente a la prestación efectuado por los usuarios de este.

La erogación presupuestaria pública anual para el Poder Judicial, como el gasto de los usuarios del servicio de justicia, podría no reducirse en su monto pero sí ganar en eficiencia y eficacia. Para que sea más eficiente, los fondos recibidos por ambos conceptos tendrían que gastarse con mayor precisión con la posibilidad de algún ahorro o alguna mejora del servicio. Para que sea eficaz, 
dicho dinero tendría que gastarse asegurando la continuación del servicio sin rivalidad y con las mismas exclusiones en su consumo. ¿Cómo podrían lograrse ambos resultados?

¿Qué ocurriría si distribuyésemos la prestación del servicio de justicia en más etapas con menor escalabilidad entre estas? La pregunta tiene dos premisas que debemos explicar: etapas y escalabilidad.

El servicio de justicia se ejerce en etapas, de las cuales actualmente identificamos tres: una central, una anterior y una posterior. La etapa anterior o prejudicial comprende todos los medios alternativos que buscan solucionar o interrumpir conflictos evitando llegar a la etapa central. Aquí encontramos a la negociación, la mediación y la conciliación, por ejemplo. La etapa central o judicial, propiamente dicha, abarca desde la demanda hasta la sentencia 0 , comprensivamente, hasta que lo resuelto queda consentido o ejecutoriado (firme y con calidad de cosa juzgada). La etapa posterior se refiere a la ejecución de lo resuelto en sede judicial, en la cual se emplean mecanismos de ejecución forzada como también cumplimiento voluntario, reapareciendo la posibilidad de negociar la ejecución, de celebrar contratos acerca del cumplimiento, de novar la obligación, entre otras opciones. Las tres etapas importan presupuestos previos y gastos concurrentes. Si bien con distintas fuentes, son dos conceptos económicos que axiomáticamente - como queda indicado- acompañan al servicio de justicia ${ }^{2}$.

Las tres etapas descritas funcionan y discurren sobre una lógica sucesiva: una sigue a la otra, una sirve de requisito a la siguiente. El servicio de justicia se cumpliría de manera escalable, al avanzar de una etapa a otra buscando alcanzar el fin del servicio mismo, el cual

2 Las jurisdicciones penal y arbitral tienen sus propias particularidades y etapas, diferentes internamente pero teleológicamente similares en una visión conjunta. 
es solucionar las controversias jurídicas surgidas en la sociedad. Incluso esa lógica habita dentro de la etapa central, a través de la sucesión de actos procedimentales y de las jerarquías resolutivas (nociones que comprometen todo nuestro arsenal de conceptos procesales).

Volvamos a nuestra pregunta. Esta plantea y sugiere la posibilidad de más etapas y menos escalabilidad. ¿Qué significa ello? Pues que el servicio de justicia se extienda en más etapas y que todas estas sean capaces de solucionar la controversia surgida sin necesidad de escalar a la siguiente. Esa extensión sería incluso mayor, pues con lo visto en el tema educativo, debería formar a los ciudadanos y evitar el surgimiento de controversias; solo después aparecerían las etapas que den solución a las diferencias ya surgidas con sentido no escalable, tanto estructural como finalista.

¿Advirtió usted las implicancias económicas de lo anterior? Son varias. En principio, el presupuesto asignado se aplicaría con mayor laxitud, lo mismo que los pagos o las tasas de los usuarios, los cuales deberían recabarse en ocasiones más desconcentradas. La segunda es que las controversias podrían evitarse en considerable número, con un compromiso menor de ese presupuesto y de las economías de los usuarios. Otra consecuencia sería que, surgidas las controversias, estas podrían ser atendidas con la participación directa de los usuarios en la solución, acompañados de asesoría profesional permanente, de manera más distendida y más cerca de los usuarios mismos, evitando muchas externalidades negativas. Un cuarto efecto sería la mayor difusión, la aplicación y el desarrollo de medios alternativos de solución de conflictos, tales como la mediación, la conciliación, el arbitraje popular (atención a eso) y otros. En quinto lugar, figuraría el hecho de alcanzar la etapa jurisdiccional solo en aquellos procesos que justificadamente demanden los recursos del Estado para su solución (tiempo, personas, arquitectura 
digital y todo tipo de «logística»). Un sexto efecto sería la formación de un esquema que permitiría la construcción de una jurisprudencia más razonada (por el sistema en su conjunto), precisa (respecto de casos filtrados por todo el sistema) y fuerte (mayor predictibilidad, por todo lo anterior), con la revalorización del rol de la Corte Suprema. Otra consecuencia sería que todas las etapas anteriores podrían funcionar de manera más descentralizada, tanto física como tecnológicamente, reduciendo costos en cada etapa. Tendríamos como último efecto - por ahora, sin cerrar la lista- a la constitución del sistema de justicia en una herramienta de levantamiento de información no solo legal o jurisdiccional, sino también social, económica o demográfica, que podría cruzarse con otros sistemas en favor de labores educativas, sanitarias, de emergencia u otras.

\section{LAS TECNOLOGÍAS DEL HOY Y DEL MAÑANA}

Este es el punto de quiebre, una realidad compleja de herramientas y posibilidades que han llegado para impregnarse en todo, para cambiarlo todo, para transformar la sociedad, el derecho y el ejercicio de la función jurisdiccional. También hay riesgos. Nuestros conocimientos en derecho sustancial o procesal, nuestras habilidades o nuestra experiencia de despacho no serán suficiente contención. Detengámonos a exponer esto.

La ciencia es el conjunto de conocimientos que el ser humano adquirió desde sus inicios como especie, que ha madurado a lo largo de los siglos y en las distintas civilizaciones. Dicho conocimiento - generado por el azar, la curiosidad, la creatividad, la investigación, la experimentación y la necesidad - es luego ordenado y clasificado de acuerdo con diversos criterios, así como sometido a posteriores revisiones y cuestionamientos. La teoría resultante es 
llevada a la práctica para atender a las necesidades de la realidad, lo que genera nueva información que retorna. La ciencia es una realidad dinámica: es el producto de la suma, el estudio, la aplicación y la mutua renovación de la teoría y de la práctica (Jiménez Vivas, 2020, p. 174).

La ciencia nunca se aplicó directamente sino que lo hizo a través de la tecnología. El trabajo lítico, el control del fuego, la polea, la rueda, la escritura, la pólvora, la imprenta, la electricidad, etc., han realizado la ciencia en la práctica y la han retroalimentado. Ese rol es asumido actualmente por la internet (Jiménez Vivas, 2020, pp. 174-175).

Han existido cuatro tipos de tecnologías. La primera aumenta nuestra fuerza o resistencia física, destreza y capacidad de recuperación (el arado, la aguja de zurcir, el avión de combate). El segundo grupo extiende el alcance o la sensibilidad de nuestros sentidos (el microscopio, el amplificador). Un tercer grupo de tecnologías nos permite remodelar la naturaleza para que sirva mejor a la satisfacción de nuestras necesidades o nuestros deseos (el embalse hidráulico, la píldora anticonceptiva o el maíz genéticamente modificado). En el cuarto grupo figuran las herramientas que nos sirven para ampliar nuestra capacidad mental, para encontrar y clasificar la información, para formular y articular ideas, para compartir métodos y conocimientos, para tomar medidas y realizar cálculos o para ampliar la capacidad de nuestra memoria (el ábaco, el sextante, el globo terráqueo, el libro, la máquina de escribir, la escuela, la biblioteca, la computadora o la internet). (Carr, 2016, citado por Jiménez Vivas, 2020, p. 175).

Pero el tema no ha quedado allí. Desde hace ya varios años, ha irrumpido un nuevo grupo de tecnologías, cuyas características las sitúan entre el segundo y cuarto grupo indicados. Hablemos aquí un poco - muy poco en realidad- de la telepresencia, de 
la realidad aumentada, de la blockchain y de la inteligencia artificial. ¿En qué consisten realmente estos fenómenos tecnológicoeconómico-sociales? ${ }^{3}$

La telepresencia es la tecnología que permite burlar las distancias espaciales y diferencias horarias, pero no como lo hace la página web, el correo electrónico o, más aún, la mensajería instantánea, sino además estableciendo una presencia sincrónica perfecta entre dos o más personas que se encuentren en lugares y zonas horarias distintas. No se trata de una videoconferencia similar a los softwares Skype, Teams, Zoom o Hangouts Meet, con imagen más nítida o mejor sonido, sino de la coincidencia física total de los participantes, mediante su ubicación en ambientes con igual decoración e implementación y a través de pantallas con visión profunda y amplia, acompañadas de buen sonido y con todo tipo de detalles. En el derecho, esto equivaldría a lograr la completa inmediación en la red: el discurso, el análisis y la exposición fluirían ordenadamente, la lectura u oralización de todo documento sería posible y el examen a cualquier persona se realizaría sin límites técnicos.

La realidad aumentada es otra tecnología que conocemos a través de su frecuente empleo en recientes películas de ciencia

3 Existen otras tecnologías: la «internet de las cosas» o IoT (para la que no hemos identificado una aplicación dentro del servicio de justicia), o la «nube» (que está teniendo aplicación en una primera capa como repositorio de información, sin que se aprecie tampoco alguna próxima utilidad de capas superiores). Si hubiese alguna novedad para ambas tecnologías en sede jurisdiccional, la incluiremos en otra publicación. De otro lado, se precisa que la mención de seis tecnologías no implica un sometimiento pasivo al "capitalismo de plataformas», sino una participación activa y propositiva en este, a partir de la información, las características y las necesidades de nuestros servicios; desempeñando un rol activo como consumidores y - por qué no- algún día como desarrolladores.

4 Susskind (2020, pp. 295-294) refiere las experiencias de la British Telecom en Martlesham, Inglaterra, en 1997, y otra de Cisco en el centro de Londres en el 2006. Los años referidos nos muestran una tecnología que, en la actualidad, ya cuenta con avances muy significativos. 
ficción. La visión del mundo exterior del protagonista se superpone con información como, por ejemplo, el nombre de un transeúnte, la ruta hasta su destino, la estructura de un edificio, sea en formato visual o auditivo. La realidad aumentada o realidad híbrida está diseñada para mejorar y complementar la percepción de la realidad ofreciendo información adicional acerca del mundo que nos rodea. Tiene dos direcciones. Una facilita información complementaria y otra oculta aspectos complejos o intensos del mundo real (Susskind, 2020, pp. 296-297).

La realidad aumentada no sustituye a la física sino que imprime datos informáticos al mundo real. El usuario queda inmerso en un ambiente reconstruido a través de simuladores, donde sensores diseñados al efecto producen una impresión de aparente realidad (Mosches y Volfzon, 2015, p. 33). La realidad aumentada se estructura sobre la base de elementos diegéticos o reales, se compone de elementos no diegéticos o agregados para mejorar la experiencia del usuario, y ofrece a este una visión estereoscópica que hace posible percibir en tres dimensiones todos los objetos cercanos y en dos aquellos lejanos (por ahora). Desde la óptica jurídica, estamos ante una herramienta capaz de superar brechas informativas, idiomáticas y de acceso a la justicia, y hábil para auxiliar efectivamente a personas con diversas discapacidades.

Referirnos a la blockchain, en cambio, es tocar un tema mucho más amplio y relevante. La tecnología de bloques encadenados es de tipo fundacional y revolucionaria. Su antecedente o inspiración estaría en las grandes monedas de piedra en forma de disco usadas por los pobladores del pequeño estado Yap (integrante de la Federación de Estados de Micronesia), pero principalmente en el sistema de circulación centralizado que todos los pobladores conocen y consienten, que hace innecesario el traslado de las pesadas piedras ${ }^{5}$.

5 Ver el documental de Pancorbo (1993), en particular desde el minuto 27 hasta el 35. 
La blockchain es un conjunto de unidades que permiten ingresar, controlar y compartir información en distintos computadores, memorias o servidores. Estas unidades, conocidas como «nodos», se encuentran interconectadas y situadas al mismo nivel. Operan siguiendo un único protocolo informático o conjunto de reglas que rigen todas las características y funcionalidades del conjunto. Después de un primer bloque (o bloque "génesis»), se van sumando uno a uno los demás, en la medida que las personas que participen acepten las reglas comunes y agreguen información a la cadena desde su nuevo nodo. La cadena que se conforma con los nodos interrelacionados no es controlada por alguno de estos, de tal forma que se convierte en una red descentralizada de información en permanente actualización. La data así compartida resistiría el peor accidente en la red, bastaría que uno de los nodos la conserve ${ }^{6}$. ¿Qué empleos o servicios podría brindar una estructura similar al derecho? Muchísimos. La respuesta un poco más adelante. Sigamos.

Las unidades de la cadena de bloques o nodos no son todas iguales. Algunos nodos son ligeros, pues no poseen una copia completa de la base de datos descentralizada sino información básica o mínima. Son los llamados «nodos wallet», que permiten efectuar transacciones de diverso tipo, destacan aquellas efectuadas con criptomonedas. Otros nodos son completos, ya que por oposición a los anteriores, sí comprenden una copia de la base de datos descentralizada. Un tercer tipo de nodos son los «nodos mineros», que se encargan de la tarea de validar todas las actividades que se realicen en la blockchain, y luego de cumplirla empaquetan dicha información, enviando esta a todos los nodos para que la incorporen en la base de datos descentralizada (Palomino, 2019, pp. 283-284).

6 «Blockchain.com» fue lanzada el 30 de agosto de 2011 por Peter Smith, Ben Reeves y Nicolas Cary. Sin embargo, la primera cadena de bloques fue «Bitcoin», lanzada entre los años 2008 y 2009 por una persona o agrupación de personas denominada «Satoshi Nakamoto». 
¿Cuál es el primer ámbito jurídico en el cual ha explotado la tecnología blockchain? La actividad financiera. Por oposición a las bases de datos centralizadas de los bancos, la blockchain permite a los tenedores de capitales y a los buscadores de financiación poseer toda la información que necesitan. La existencia de las monedas virtuales bitcoin (BTC), bitcoin cash (BCS), litecoin (LTC), EOS (EOS), ether (ETH), dogecoin y otras tantas - todas operando a partir de redes blockchain-, así como la incursión de las «finanzas descentralizadas» (DEFI), son prueba de ello.

Un segundo espacio jurídico será el del derecho de bienes (nuestros tradicionales derechos reales), en el cual muchos bienes pueden ser protegidos, difundidos y comercializados por sus propietarios o autores mediante la blockchain. Es lo que viene ocurriendo con las obras de arte, las cuales, digitalizadas, pueden ser aprovechadas económicamente por sus autores de diversas maneras mediante los NFT o «tokens no fungibles» (Caparroso, 2021), además de servir para la obtención de préstamos. El tema abre muchas posibilidades contractuales, muchas de estas realizables en la misma blockchain mediante los denominados smart contracts.

Otro ámbito es el derecho registral, cuyos principios (legalidad, legitimación, fe pública, publicidad y tracto sucesivo) son compatibles con la tecnología blockchain (Palomino, 2019, pp. 292-297). En cuarto lugar, la cadena de custodia en las investigaciones penales puede organizarse mejor en una blockchain, utilizando como criterios qué especies se hayan encontrado en las diligencias de investigación y en cuántas de estas hayan sido recogidas. En derecho procesal podríamos imaginar a los abogados de una materia o un territorio inscritos todos en una blockchain, sus procesos aparecerían como pequeñas cuentas (como nodos de una wallet) y recibirían por esta vía todas sus notificaciones (o hasta presentarían «escritos»), con la garantía de la presencia de todos los abogados participantes y sin distraerlos en demasía. 
Cabe terminar este punto indicando que ya existen iniciativas que, centrándose en nichos fuera de los ámbitos judiciales, de tipo estrictamente comercial o arbitral, o conflictos con requerimientos probatorios menores, promueven el ejercicio de la función jurisdiccional fuera de los límites estatales, completamente bajo dirección privada, dentro de entornos de la blockchain. El primero fue quizá el de eBay con su «eBay's resolution center», mediante el empleo de dos mecanismos de resolución de disputas en línea ${ }^{7}$. En América tenemos la iniciativa de «Kleros», autocalificada como la herramienta de disrupción de la blockchain en materia de transformación de sistemas de justicia, la cual plantea un servicio de justicia privado, totalmente excluyente de aquel estatal, mediante jurados incentivados para resolver con predictibilidad tanto por un algoritmo como por un beneficio económico, y ofreciendo una ejecución automatizada e inmediata de lo resuelto ${ }^{8}$.

La inteligencia artificial será la última tecnología acerca de la cual trataremos brevemente, aunque también nos convocará más líneas. Debemos empezar reconociendo que se trata de un sustantivo que ha recibido un empleo erróneo y diverso, sea por exceso, por imprecisión o por indefinición de su contenido. Empecemos clarificando el panorama en torno a la inteligencia artificial, hagamos algunas clasificaciones, definamos sus alcances, para luego explorar en qué medida puede ingresar en el mundo del derecho y de la función jurisdiccional.

7 Siguiendo a Susskind (2020, p. 128), eBay llegó a resolver hasta el 2017 la cifra de 60 millones de desacuerdos entre comerciantes y clientes, utilizando para ello dos mecanismos de resolución online de conflictos (ODR): una negociación online estructurada dirigida por el personal de eBay, sin intervención de terceros, y un proceso de adjudicación online.

8 El director de Kleros (https://kleros.io/) promocionó un evento en el 2020 con un video en el cual preguntaba "¿Imaginas un mundo sin banqueros, sin abogados, sin políticos?» e indicaba que la blockchain «está disrumpiendo a las finanzas, a las leyes y a los gobiernos». 
Una aproximación al tema nos lleva a identificar una primera concepción de la inteligencia artificial comprensiva de las distintas herramientas, los procedimientos y las técnicas utilizadas para la aplicación de la tecnología. Esta es seguida por una segunda concepción de carácter funcional u operacional que se refiere a los programas que dirigen a tales herramientas. Hasta aquí, tenemos una visión de la inteligencia artificial dual, referida a las máquinas informáticas o hardware y a los programas informáticos o softwares. La primera etapa evoca lo que conocemos como tercera revolución industrial, aquella que a partir de 1969 llevó al mundo hacia una producción electrónica y automatizada, mientras que la segunda apunta a la cuarta revolución industrial, en pleno desarrollo.

Podemos clasificar a la inteligencia artificial. En primer lugar, encontramos a los sistemas que desarrollan tareas claramente definidas y limitadas, que conforman la inteligencia artificial débil o específica, carente de todo estado cognitivo. En segundo lugar, se ordenan las máquinas y los programas capaces de realizar la mayoría de las tareas que pueden desempeñar los seres humanos, agrupadas en una inteligencia artificial fuerte o general, poseedoras de grados de conciencia. En tercer lugar, podemos considerar una «superinteligencia» artificial, integrada por sistemas que funcionan a un nivel muy superior a las capacidades actuales de los seres humanos (Susskind, 2020, pp. 307-308). En la actualidad, los programas y las máquinas que hemos desarrollado pertenecen al tipo débil o específico e incursionan en el amplio espacio de la clase fuerte o general; la superinteligencia sería aún una construcción teórica.

La inteligencia artificial no es más que el conjunto de softwares que están en la base y permiten el funcionamiento de nuestros sistemas informáticos. El sustantivo «inteligencia» esconde la pregunta, la duda o la certeza acerca de la forma en que dichos programas «aprenden», es decir, sobre cómo incrementan, hacen más variado y más preciso su trabajo. $\mathrm{Al}$ respeto, son tres los conceptos que se 
encuentran en la base de la inteligencia artificial: los datos, la capacidad de procesamiento y los algoritmos. El avance paralelo y conjunto de los tres permite a la inteligencia artificial lograr desarrollos incrementales (cuantitativos) y extensiones funcionales (cualitativas).

El mundo jurídico ya está recibiendo la influencia de la inteligencia artificial. Las legaltechs cada día incursionan más en la prestación de servicios online, en la redacción de contratos y documentos legales, así como en la investigación legal con softwares especializados. Nuevos espacios jurídicos como el análisis de datos legales, las operaciones legales, el análisis de procesos legales o la dirección de procesos legales utilizan la inteligencia artificial. Las empresas fintech y los softwares de gestión de despacho legal también lo hacen. Asimismo, es común encontrarla en las áreas de atención al usuario (los boot, por ejemplo, están ya por todas partes), contratación en línea u otras de diversas empresas. Las áreas legales del sector público aún no experimentan un gran empleo de la inteligencia artificial, situación que poco a poco cambiará. Al menos, en otras latitudes ya existen tribunales que utilizan inteligencia artificial en los servicios que prestan a sus usuarios ${ }^{9}$.

9 De acuerdo con Susskind (2020, p. 204), herramientas de inteligencia artificial son empleadas para ayudar a redactar reclamaciones y alegatos y para asistir a las partes a analizar los posibles resultados de un litigio, como el introducido en el 2017 en la «First Intermediate People’s Court» de Pekín, que al parecer podría responder a más de 40000 preguntas legales diferentes.

Por otro lado, la Comisión Europea —órgano de la Unión Europea (UE) — está preparando un ordenamiento jurídico para la inteligencia artificial (IA) conformado por un Reglamento (máximo rango europeo) y un Plan Coordinado entre todos los Estados miembros. Su objetivo será reforzar el liderazgo de la UE en temas de IA, centrarla en el ser humano (IA confiable, sostenible y segura) y fomentar la excelencia (en su creación, investigación e innovación). La función jurisdiccional será alcanzada en temas diversos (derechos fundamentales, identificación de personas, probática y otros). 


\section{UNA FUTURA ESTRUCTURA PARA UN NUEVO SISTEMA DE JUSTICIA}

Nuestras cortes superiores, imaginadas sobre los territorios de las intendencias virreinales (cuya subdivisión posterior caracterizó al siglo XX y continúa en el siglo XXI), son el esquema territorial que rige a nuestro Poder Judicial. En cuanto al organigrama institucional, este empieza con los juzgados de paz y se erige hasta las salas supremas, siguiendo el mismo encuadramiento jerárquico republicano (con cambios de denominaciones y aparición de diversas secciones especializadas). Desde su fundación, nuestra organización se ha dedicado a enfrentar conflictos ya surgidos en la sociedad, asumiendo la función de solucionarlos con la aplicación del ordenamiento jurídico, sea reconociendo derechos, asignándolos, estableciendo restricciones, atribuyendo responsabilidades o imponiendo sanciones. Lejos de superar su diversa problemática (entre la que destaca la variada e indomable carga procesal), la pandemia nos mostró a un Estado que, luego de no visionar el futuro de la transformación digital, ha tenido que saltar hacia el interior de esta con herramientas limitadas y con pocas competencias personales no aprestadas para el nuevo entorno sociotecnológico.

Todo lo anterior discurrió durante los ya doscientos años de vida republicana sin considerar la influencia de los ámbitos educativo, económico y tecnológico antes presentados; sin advertir que la organización así planteada toleró la generación de costos de todo tipo, de externalidades negativas y de brechas socioculturales que en su conjunto complicaron y todavía dificultan la formación de un proyecto de nación para nuestro tercer siglo de independencia (¿tenemos alguno claro para el bicentenario?). Los márgenes de deslegitimación que nos asaltan (junto a otras organizaciones del Estado y de la sociedad) brotan de diversas causas, pero fluyen desde lo estructural. Hemos tenido planes de reformas, nunca uno de transformación. Bajo el argumento de rechazar el peligro, el 
apresuramiento o la imprudencia, se ha consagrado un estado de cosas (de discurso, de redacción, de estilo gerencial, etc.) distante de las necesidades y expectativas de los usuarios de nuestro servicio, que a través de las décadas han cambiado, se han reorganizado y muestran facetas socioeconómicas inimaginables incluso a fines del siglo XX.

¿Qué nos dice la variable educativa? Que el espectro de la función jurisdiccional debe empezar allí, de manera consciente y articulada. ¿Qué nos informa el ingrediente económico? Que la función jurisdiccional debe extenderse, salir de sus espacios tradicionales e incursionar en los ámbitos de la sociedad a la cual atendemos, disgregando sus funciones y poderes de manera paulatina, en etapas destinadas a lograr los fines de ordenación y pacificación de la sociedad. ¿Qué nos señala la clave tecnológica? Que es posible formular una reorganización sobre sus hombros, considerándola como una premisa que crecerá en el siglo XXI, haciendo imposible no otorgarle un lugar preferente, bajo pena de mayores costos y deslegitimación ante la población.

Sin pretensiones de dar una receta fija o única, y alejados de cualquier dogma y de plazos cortos, vemos que una política jurisdiccional para el siglo XXI tiene que establecerse cuidando que marche a la par de la sociedad. La identificación de algunos problemas sociales con innegables y distintas consecuencias jurídicas e impacto en el sistema de justicia constituye el reconocimiento de que la función jurisdiccional debe pensarse en una primera etapa desde el sistema educativo. La educación primaria y luego la secundaria son la primera posibilidad de formar ciudadanos con conocimientos simples pero básicos y armónicos sobre elementos centrales de su futura interacción como ciudadanos con el Estado y con la sociedad. Y no nos referimos a un cúmulo de información sino a materias específicas (hemos presentado algunas) que tienen un aspecto teórico, pero también fines formativos prácticos, 
alcanzables con el empleo de las tecnologías que resulten más idóneas y ofrezcan mayor uso. Las brechas digitales serán un desafío de necesaria atención, pero de ninguna forma un obstáculo insalvable.

En la memoria queda el curso Educación Cívica, con una hora arrinconada al inicio o final de la jornada y sometida a cualquier actividad extracurricular que se programase, lo que desintegraba toda posibilidad para dicho curso. Se trata de un triste antecedente - de una oportunidad perdida- que no replanteamos. Hemos visto cómo el actual currículo educativo contiene elementos que -identificados y ordenados programáticamente- permitirían, a través de más de una materia escolar, cumplir con la formación en los temas que aquí proponemos. Existen especialistas en el tema que con mayor autoridad podrían efectuar muchas sugerencias. Un mapeo de actores en la etapa de diseño de la política jurisdiccional debe considerar a estos profesionales y al segmento estatal o privado que los agrupa. La información manejada en torno a esta propuesta debería ser un insumo objeto de publicidad como premisa básica en otros espacios jurisdiccionales.

Lo que seguiría sería una segunda etapa. Este momento o esta franja nacional tendría un carácter básicamente informativo y de refuerzo. Partiendo de resúmenes de la educación recibida en las escuelas, esta etapa estaría destinada a informar a todas las personas acerca de lo que significa relacionarse con otras dentro del ordenamiento jurídico, en qué consiste tal o cual contrato, cómo puedo solucionar cualquier conflicto que emane de estos, cuáles son los alcances de tal derecho o de tal obligación, cómo puedo ingresar al ámbito jurisdiccional, sobre qué versa tal o cual litigio, etc., siempre en términos generales. Esta franja manejaría estilos de discurso, de redacción, de disposición física, de diseño de documentos, de colores y formas intencionalmente distintos de aquellos en general jurisdiccionales. 
Sería una labor extendida, a cargo de los órganos descentralizados de base del Estado: las municipalidades. Podrían participar algunas ONG u otras instituciones; incluso la Defensa Pública del Ministerio de Justicia podría adelantar alguna de sus tareas. Todos los órganos participantes tendrían que manejar similar información, por medio de abogados in house (integrantes de la estructura de tales organizaciones o no) bajo supervisión del Ministerio de Educación y del Poder Judicial. La intervención del primero llegaría solo hasta este punto.

El siguiente momento de actuación del sistema de justicia, o tercera etapa, sería una destinada a evitar el surgimiento de conflictos. Este sería el espacio para formas autocompositivas como la negociación y la mediación. Estas podrían presentarse sucesiva o alternativamente, en infraestructura presencial o digital apropiada para ello, con un registro de las actividades realizadas, con actuaciones caracterizadas por su informalismo en favor de un mejor clima, propicio para el trato directo, teniendo al lado los recursos profesionales necesarios que permitan formalizar conforme a ley cualquier solución a la que puedan arribar los usuarios. Es un terreno para la gestión privada, con costos de acceso que una amplia red de abogados con auxilio tecnológico haría disminuir, además de recojo de información permanente y concurrente por parte del Poder Judicial, como ente rector del sistema de justicia. Esta etapa se cumpliría sobre estilos de discurso, de redacción, de disposición física, de diseño de documentos, de colores y formas intencionalmente diferentes de aquellos en general jurisdiccionales. Es un campo para la apertura interdisciplinaria.

La negociación tiene como base el inicio de comunicación entre las partes de un conflicto, sin intermediarios, para intercambiar puntos de vista en búsqueda de una solución. Los intervinientes llegan a puntos precisos y claros, con el fin de estructurar de manera conjunta un acuerdo por el cual maximicen sus resultados 
en mutuo beneficio, obtengan más ganancias que pérdidas y resuelvan la controversia que los separa (Pinedo Aubián, 2017, p. 78). Por su parte, la mediación es otra forma autocompositiva que se realiza con la participación de las partes y de un tercero, el cual colabora con estas cumpliendo el rol de moderador y facilitador, sin formular recomendaciones ni sugerencias sobre el tema objeto de la diferencia (Pinedo Aubián, 2017, pp. 79-80). Pensamos que sería la ocasión para que intervengan unos importantes agentes del sistema de justicia: los colegios de abogados. También sería un espacio para la participación de las facultades de derecho a través de sus oficinas especializadas, con el consiguiente acercamiento de sus estudiantes al sistema de justicia así estructurado.

La cuarta etapa del sistema de justicia tendría como objetivo solucionar los conflictos que surjan antes de que se expandan y generen más costos a la sociedad (de tiempo, de dinero y demás recursos, incluso de salud mental). Sería una etapa pensada para formas heterocompositivas de solución de contiendas. Nos referimos fundamentalmente a dos: a la conciliación y el arbitraje popular. También sería un espacio para la gestión privada con recojo concurrente de data por parte del Poder Judicial como ente rector, así como una oportunidad para el trabajo interdisciplinario.

La conciliación es la acción destinada a componer, concordar o avenir a las partes en conflicto con el objeto de evitar un pleito o concluir el ya iniciado, realizada con la intervención de un tercero con un rol más activo que el de un mediador, pues no solo guía el procedimiento y actúa como facilitador entre las partes, sino que, a diferencia de este, tiene la facultad de proponer a las partes fórmulas de solución no vinculantes, las cuales pueden ser aceptadas por estas (Pinedo Aubián, 2017, pp. 80-81). Pensamos que esta etapa también sería un escenario adecuado para el arbitraje popular, que debería ser promovido previamente para su inclusión en los diversos actos jurídicos que se puedan celebrar, asegurando 
de antemano la existencia de una vía de solución para cualquier desavenencia. Es aquí aplicable lo indicado acerca de los colegios de abogados y de las facultades de derecho al tratar la tercera etapa.

La difusión de las herramientas de solución de conflictos en todo el país permitiría reducir los costos a niveles que no dificulten el acceso de los ciudadanos. Tanto la conciliación como el arbitraje tendrían que realizarse dentro de una infraestructura presencial o digital idóneas para sus fines, con los recursos necesarios para formalizar inmediatamente cualquier solución a la que lleguen las partes intervinientes. Los estilos de discurso, de redacción, de disposición física, de diseño de documentos, de colores y formas también tendrían que gestionarse con oposición a los siempre utilizados en sede jurisdiccional.

Recién en la quinta etapa encontraríamos a la jurisdicción propiamente dicha, como agente heterocompositivo estatal representado por sus juzgados y salas. Pero no serían estos los mismos órganos que conocemos, sino otros distintos que inicien, implementen o sigan algunos de los diversos «elementos de la jurisdicción del futuro", que hemos descrito en nuestro artículo del mismo nombre (Jiménez Vivas, 2020), u otros que desarrollen mejores criterios. En apretada síntesis, esta tercera etapa debería albergar una jurisdicción moderna con competencias personales medidas, con actores de política considerados en su diseño, con unidades informatizadas centralizadas de gestión de la información específica de los procesos judiciales, con unidades informatizadas descentralizadas de gestión de la información general de los mismos procesos, con mensajerías e identidades digitales que den efectividad a las notificaciones y toda comunicación, entre varias sugerencias que, con antelación, podrían entenderse como muy onerosas, cuando no es así.

El esquema propuesto generaría un efecto adicional: revaloraría la misión esencialmente casatoria de la Corte Suprema. A través de sus salas, esta tendría como su prioridad la generación de 
jurisprudencia que interprete nuestro ordenamiento jurídico. Esta circunstancia tendría un efecto favorable sobre el presupuesto judicial y evitaría muchos costos a la sociedad, tema este acerca del cual ya se ha escrito.

\section{IDEAS FINALES}

La interdisciplinariedad es una de las claves del futuro. Contra lo que pudiese pensarse de manera rápida, esta no representa dispersión, caos o superficialidad, sino todo lo contrario, dado que impone un nuevo orden, una renovada visión, distintos métodos y una apertura de criterios que suman: cualquier objeto termina revelando sus secretos ante más y diferentes ojos, ante disímiles observadores y con tiempos y técnicas distintas. En realidad, la interdisciplinariedad es una apuesta contra lo rápido, lo fácil y lo superficial, que observa una planta desde la raíz hasta todas las hojas para identificar si esta es una mala hierba o un árbol que dará sombra, cobijo, frutos, madera y más.

Un ejercicio interdisciplinario, sistémico y holístico nos ha permitido presentar una noción básica de lo que podría ser una mejor estructura de la función jurisdiccional como sistema funcional, como política pública nacional, como servicio público orientado a mejorar la experiencia de nuestros usuarios, como elemento formador de ciudadanos, como oportunidad para atender no solo brechas tecnológicas, sino también antropológicas y sociológicas (mediante los estudios correspondientes), como ocasión para reelaborar nuestros procesos comunicativos (no solo informativos, pensando en el «otro», en el que es «distinto») y, en general, como parte de un proyecto de nación hasta hoy inconcluso. Esta propuesta - con nuestros propios fundamentos- continúa las ideas vertidas en Jiménez Vivas (2020), pero, además, abandona la noción de «función jurisdiccional» y salta hacia la de «sistema de justicia». Hemos organizado la propuesta en cinco etapas. 
Una directriz común a todas las etapas sugeridas es compartir una matriz tecnológica amplia, diversa, intensiva y en crecimiento. Aun cuando ya hemos referido el tema en cada etapa, cabe detenernos a explicar algo más. Quedan presentadas algunas tecnologías, las cuales, si bien no son nuevas, se encuentran en un proceso de avance hacia todas las actividades que se cumplen dentro de la empresa privada, la sociedad, el Estado. Estas tecnologías nos ofrecen un sinnúmero de oportunidades para aprovechar, pero también presentan riesgos que debemos conocer. No estamos ante un cambio digital, consistente en la integración de cuatro o cinco herramientas a nuestro trabajo, mientras conservamos estructuras, estilos gerenciales, flujos de toma de decisiones, discursos y redacción del pasado. Nos encontramos ante una transformación digital que debemos identificar y entender en toda su magnitud: no hacerlo solo generará al país más costos de tiempo, de dinero, de conflictividad (individual y social), de expectativas de justicia no atendidas, de deslegitimación y de salud mental. No hay que trabajar apurados, el modo urgente es inevitable en toda organización, pero su preponderancia solo significa que antes no se ordenó el trabajo. Precisamente hay que trabajar en orden. Lo más importante será empezar.

El esquema propuesto impacta sobre el trabajo legal. Una transformación compromete a todos, sistemas completos son involucrados inevitablemente: negarlo o no aceptarlo solo significa alimentar a los problemas o convertir en tales a situaciones que aún no lo eran. Como siempre, lo más importante son las personas. Queda mencionado el tema de las competencias personales, lo cual es responsabilidad del sistema educativo y luego del sistema de justicia. Las facultades de derecho y los colegios de abogados jugarán un rol importante. Con el esquema planteado u otro cualquiera destinado a aceptar, utilizar y gestionar las herramientas informáticas mencionadas, serán necesarios abogados con nuevas competencias, 
que hayan transitado por sistemas de formación, reclutamiento, selección, inducción y capacitación más exigentes, pero a su vez más diversificados, con más oportunidades en todas las etapas descritas, con especialidades y nuevas opciones que aparecerán durante la ruta. La transformación digital impactará seriamente al mercado legal, en distintas y más formas de las que ya lo ha hecho. $¿$ Deseamos acaso que todo siga igual, con los mismos problemas e insatisfacciones? En cualquier caso, la transformación digital avanza sin recabar nuestra aceptación.

¿Y cómo así la tecnología se atreve a desafiarnos? La tecnología no ha puesto estas condiciones sino nosotros mismos. Pongamos un ejemplo. Para ir a nuestra escuela o universidad, a la sede de nuestro trabajo, o si queremos visitar a un familiar (fuera de pandemia, claro está), utilizamos vehículos que pueden ser autos o buses. ¿Qué es lo que realmente deseamos, viajar en un auto o bus, o llegar a nuestro destino? Veamos otro ejemplo. Siempre hemos ido de compras a bodegas o mercados en búsqueda de abarrotes, verduras, carne o frutas para nuestra alimentación. ¿Qué es lo que realmente buscamos, visitar tiendas y mercados o conseguir nuestros alimentos? Ante el primer ejemplo, si apareciese la manera de llegar a nuestro destino sin utilizar autos o buses, nadie se empeñaría en manejar ni se preocuparía por los taxistas o los choferes de los buses, ya que podríamos lograr nuestro objetivo sin su concurso. Hemos puesto el segundo ejemplo, pues el delivery ya nos permite recibir nuestros alimentos sin tener que visitar los centros de abasto.

Los dos ejemplos nos muestran que los seres humanos deseamos un resultado, más allá de la tecnología reinante. Desenvolvemos actividades, seguimos procedimientos, asumimos costos, etc., para alcanzar un resultado o algo que se le parezca, motivo por el cual estamos preparados para abandonar esas actividades y esos procedimientos si aparecen otros que, con menor onerosidad y demora, 
nos proporcionen lo que buscamos. Todos los bienes y servicios se han sometido a esa regla durante la historia, a la cual conocemos como obsolescencia. Considerar que los servicios jurídicos en general y jurisdiccionales en especial escapan a ello es insistir en un error. De nosotros dependerá si nos sumamos a la transformación digital (aprovechando sus oportunidades y resguardándonos de sus riesgos) o si dejamos que nos consuma en su vorágine.

A manera de apunte adicional, hay otro tema que atraviesa a nuestra propuesta. No es un tema jurídico, tampoco es contable, como no es psicológico o educativo, ni militar y menos culinario, pero guarda el potencial para servir en todos estos terrenos. Nos referimos al diseño, hoy relacionado con el acceso, los costos, la confianza, la comprensión y, en general, con toda la compleja relación existente entre las organizaciones comprendidas dentro del sistema de justicia con sus usuarios. Al respecto, podemos afirmar - de acuerdo con una de nuestras fuentes - que el diseño nos llevará a desarrollar sistemas que puedan guiar a los usuarios por áreas complejas de la ley; sustituir grandes volúmenes que rigen el proceso judicial por normas más simplificadas, muchas desconocidas para los usuarios; y desglosar el proceso en partes menos imponentes y más manejables; ir más allá del texto, utilizando animaciones, viñetas, videos, organigramas y otras guías visuales (Susskind, 2020, p. 156). El diseño puede nutrirse de todas las tecnologías mencionadas y puede transitar a través de las variantes y elementos de estas.

Como otro apunte, consideramos un error la orientación del currículo de más de una facultad de derecho hacia temas y prácticas de estricto litigio. Si bien se trata de una respuesta comercial ante modelos procesales objeto de implementación en el país, estamos también ante una ficha más que se coloca luego del largo dominó de elementos que sostienen una sociedad conflictiva, una cultura del enfrentamiento, un modelo de abogado litigante agresivo, una 
fuente de más carga procesal y, en general, una postura contraria al interés de formar una nación sobre las premisas del acuerdo, del consenso, del diálogo y de la conciencia de trabajo en equipo. No nos extrañemos cuando, después, veamos a nuestros representantes enfrentados entre sí o con el ejecutivo durante meses y meses sin solución, en clara demostración de la práctica de una cultura con cuyo mantenimiento todos colaboramos (con la que todos perdemos a la larga). Podemos elegir una opción, pero que sea con la responsabilidad de aquella que descartamos. La educación a todo nivel es el punto de inicio, es central y es la ruta de reinicio. Nuestros más variados conocimientos de derecho sustancial o procesal no pueden negarlo. Entonces, ¿por qué no pensarla como parte inicial de nuestro sistema? En este trabajo hemos ofrecido varias razones para ello.

Con la economía ocurre otro tanto. Entre sus conceptos básicos aparecen algunos que nos permiten entender y reaprender la esencia del servicio de justicia como un bien que produce el Estado sin rivalidad, pero pudiendo introducir algunas exclusiones (concepto este antes explicado y de tipo económico, no de derecho constitucional, atención). Tal aproximación económica nos señala cómo una reestructuración de la función jurisdiccional podría reducir los costos de su operación, en cuanto a su presupuesto como en cuanto a los costos que emanan de los conflictos mismos, al asignar derechos o establecer responsabilidades. Lo bueno no necesariamente es caro, el tema pasa por identificar qué necesitaré mañana y gestionarlo desde hoy. Nuestra propuesta plantea un reto de gestión sistémica, con una rectoría clara, para un servicio clave e imprescindible en cualquier proyecto de nación con la visión puesta en nuestro tercer siglo como país.

Estamos seguros de que las observaciones a nuestra propuesta han brotado rápidamente a lo largo de su lectura. Si eso ha ocurrido, hemos logrado un primer objetivo: agendar el tema dentro 
del debate. Si usted se ha interesado en uno o más de los tópicos que hemos incluido, hemos alcanzado un segundo objetivo: dotar de efectivo carácter intersubjetivo a nuestros pareceres. En caso de que hayamos obtenido su acuerdo o aprobación, sí tendremos un problema: habrá surgido una obligación, la de seguir investigando acerca de esta intersección de educación, economía, política, servicio, sociedad, derecho, jurisdicción y tecnología. Como somos optimistas, asumimos esta tercera opción y la consecuencia señalada. Se trata de un largo camino que ya habíamos iniciado y que este escrito sigue, nuevos trabajos lo continuarán.

Hay viajes que debemos emprender hoy, por nuestra voluntad y a nuestro ritmo, pues mañana tendremos que iniciarlos por obligación, con mayores y variados costos, con menos herramientas preparadas y con más desacuerdos.

\section{REFERENCIAS}

Caparroso, J. (2021, 17 de marzo). Criptoartista colombiana vendió todas sus obras de estreno como NFT en menos de 24 horas. Forbes Colombia. https://forbes.co/2021/03/17/tecnologia/cripto artista-colombiana-vendio-todas-sus-obras-de-estreno-comonft-en-menos-de-24-horas/

Carr, N. (2016). Superficiales. ¿Qué está haciendo internet con nuestras mentes? Taurus.

Congreso de la República (2004). Ley n. ${ }^{\circ} 28237$. Código Procesal Constitucional. Lima: 31 de mayo de 2004. https://diariooficial. elperuano.pe/pdf/0002/5-codigo-procesal-constitucionalley-n-28237-1.pdf

Consejo Nacional de Política Criminal (2017). Adolescentes infractores en el Perú. Boletín VI-2017. https://www.oijj.org/sites/ default/files/documentos/boletin_n6_adolescentes_infractores _2017.pdf 
Defensoría del Pueblo (2019). Nota de prensa n. ${ }^{\circ}$ 175/OCII/DP/ 2019. Defensoría del Pueblo advierte preocupante aumento del trabajo en adolescentes. https://www.defensoria.gob.pe/wpcontent/uploads/2019/06/NP-175-19.pdf

Jiménez Vivas, J. E. (2020). Elementos de la jurisdicción del futuro: una experiencia web, una propuesta y una visión. Revista Oficial del Poder Judicial. Órgano de Investigación de la Corte Suprema de Justicia de la República del Perú, 12(14), 171-207. https:// revistas.pj.gob.pe/revista/index.php/ropj/article/view/298/410

Ministerio de Educación (2020). 2016-2019. Deserción escolar. En Estadística de la Calidad Educativa (ESCALE). http://escale. minedu.gob.pe/ueetendencias 2016

Ministerio de Educación (2017). Currículo Nacional de la Educación Básica. http://www.minedu.gob.pe/curriculo/pdf/curriculonacional-de-la-educacion-basica.pdf

Mosches, M. y Volfzon, G. (2015). Escuela y conectividad. Bonum.

Palomino, S. (2019). Una breve introducción a la tecnología blockchain y sus repercusiones en el derecho registral. Revista del Foro, (106), 281-299.

Pancorbo, L. (1993, 26 de septiembre). Yap, el dólar de piedra. [Documental]. Radiotelevisión Española. https://www.rtve.es/ alacarta/videos/otros-pueblos/otros-pueblos-yap-dolarpiedra/1978887/

Pinedo Aubián, M. (2017). La conciliación extrajudicial. Gaceta Jurídica.

PQS (2015, 3 de agosto). El $50 \%$ de los jóvenes de hasta 25 años tienen deudas con sus tarjetas de crédito. PQS. https://pqs.pe/ actualidad/economia/el-50-de-los-jovenes-de-hasta-25-anostienen-deudas-con-sus-tarjetas-de-credito/ 
Stiglitz, J. y Rosengard, J. (2016). La economía del sector público (4. ${ }^{a}$ ed., trad. María Esther Rabasco). Antoni Bosch editor.

Susskind, R. (2020). Tribunales online y la justicia del futuro (trad. GEA Textos). La Ley. 